\title{
Articles
}

\section{Teaching Compressed-Format Courses: Teacher-Based Best Practices}

\author{
William J. Kops, University of Manitoba
}

\begin{abstract}
This study provides insight into how highly rated instructors approached teaching compressed summer session courses, and offers a set of best practices that others might use when teaching in similar settings. Top-rated instructors indicated differences in the way they taught compressed-format summer session courses, with respect to course planning, classroom instruction, student assessment, and interaction with students. The study is of value to continuing educators, as universities are increasingly challenged to think about flexible delivery models, including teaching and learning in compressed formats.
\end{abstract}

\begin{abstract}
RÉSUMÉ
Cette étude permet de comprendre l'approche de chargés de cours très bien cotés envers l'enseignement des cours comprimés des sessions d'été, et offre un ensemble de pratiques exemplaires que d'autres pourraient choisir d'employer dans des conditions similaires. En effet, ces chargés de cours de haut calibre ont indiqué enseigner différemment les cours en format comprimé des sessions d'été en ce qui concerne la planification des cours, l'enseignement en classe, l'évaluation des étudiants et l'interaction avec ceuxci. Tandis que les universités doivent de plus en plus relever le défi de la flexibilité des modèles de transmission du savoir, incluant l'enseignement et l'apprentissage en format comprimé, cette étude vaut son pesant d'or pour les éducateurs aux adultes.
\end{abstract}




\section{INTRODUCTION}

The topic of teaching in compressed formats has long been of interest to those involved in summer sessions, because of the need to ensure the quality of courses taught in this way. The literature on teaching compressed-format courses is not extensive, but most of what has been reported supports the notion that the quality of the teaching/learning experience is comparable to when the same subject matter is taught in a longer format, particularly when the instructional quality is high. This study provides insight into how highly rated instructors approached teaching compressed summer session courses, and how their approaches differed from those used in full-length sessions. Based on these insights, a set of best practices was developed for teaching compressed-format courses. The study is of value to continuing educators, as universities are increasingly challenged to think about flexible delivery models, including teaching and learning in compressedformat courses. Taking a critical look at compressed courses taught in summer session is important not only to those who offer compressed-format courses in the summer termoften continuing education units - but also to universities more broadly.

\section{Related Literature}

The literature on teaching in compressed formats is not extensive. However, a number of researchers have commented on the effectiveness of teaching in compressed formats, based on reviews of the literature or on direct interactions during teaching in compressed-format courses, including instructors' assessments of their own experiences.

\section{Teaching Compressed-Format Courses: Does It Work?}

In a review of the literature related to the use of intensive courses in higher education, Daniel (2000) included a section on teaching practices and concluded that intensive courses stimulated discussion and fostered creative teaching. Specifically, she noted that successful intensive courses are well planned, employ organized and structured activities, utilize a multitude of teaching strategies, and focus on learning outcomes and careful student assessment. Lee and Mroczka (2002) determined from their review of the literature that time per se may be relatively unimportant if instructors deal effectively with the learning environment. In particular, they proposed instructors set clear learning outcomes, recognize individual learning differences, create positive classroom environments, consider using short but frequent assignments, and provide regular feedback and support to students. Building on her earlier research findings and those of others, Scott (2003) concluded that intensive courses have benefits, including more focused learning, more collegial classroom relationships, more in-depth discussions, and stronger academic performance when certain instructional and classroom attributes are present.

Canadian Journal of University Continuing Education / Vol. 40, No. 1, spring 2014

Revue canadienne de l'éducation permanente universitaire / vol. 40, no 1 printemps 2014

http://ejournals.library.ualberta.calindex.php/cjuce-rсepu 
Teaching Compressed-Format Courses

Some of the key attributes are instructor enthusiasm, active classroom interaction, good course organization, and relaxed learning environments. Gaubatz (2003), as part of a review of current research that examined course scheduling formats and student learning, determined time-intensive courses (including courses taught in summer session) compared favourably in terms of student performance to semester-length courses, regardless of discipline. Overall, she indicated that intensive courses were "found to foster academic achievement, stimulate group discussion, improve studentfaculty interaction, and promote active learning and creative teaching techniques" (p. 3). Martin and Culver (2007), in a comprehensive review of the literature on teaching/ learning in compressed courses, concluded compressed courses are not inferior to courses taught in a full-length format-and, depending on the context, may be superior.

More directly, Wilson (2007) talked about instructional design for summer sessions in terms of four perspectives: a vision of the student, course-content selection, evidence-based assessment, and organization and delivery of content. In particular, she pointed to the importance of prioritized learning that distinguishes between "must knows" (prerequisite knowledge and foundational ideas), "need to knows" (less critical at the moment but must knows later), and "nice to knows" (can be put off without jeopardizing baseline knowledge). Wilson recommended that when instructors teach compressed courses in summer session, instructional strategies and methods should focus on "must knows" and "need to knows." Similarly, Swenson (2003) focused on learning outcomes as a measure of learning quality in accelerated (intensive) courses. In his view, thinking in terms of managing learning versus transmitting information opens up possibilities for planning courses differently, regardless of the format. This learning outcome focus potentially creates opportunities to plan more effectively to teach in compressed formats, because rather than simply trying to fit the semesterlength content into a more compressed format, instructors can focus on what needs to be learned and plan accordingly. In a study that included interviews with faculty, Shoemaker (2009) reported instructors were enthusiastic about teaching in summer session. In particular, they liked the smaller class size, the more casual atmosphere, and the increased interaction with students. While challenges resulted from the faster pace and physical demands of teaching in a compressed format, these instructors agreed that the quality of teaching in summer session was comparable to, if not better than, when teaching in the full-length term.

Anastasi (2007) looked at academic performance and course evaluations in identical courses taught in summer session and in the full-length term. Her results determined that overall academic performance was similar and course/instructor evaluations were comparable, regardless of the teaching format. Lutes and Davies (2013), in a study at a single US-based university, looked at two points of comparison between courses taught over a full semester versus in a compressed format: grades students earned in comparable courses, and student reported workload. They found that grades earned were not significantly different, while the difference in reported workload was small

Canadian Journal of University Continuing Education / Vol. 40, No. 1, spring 2014

Revue canadienne de l'éducation permanente universitaire / vol. 40, no 1 printemps 2014

http://ejournals.library.ualberta.calindex.php/cjuce-rcepu 
when comparing formats/sessions (i.e. full-length to compressed) but significant when comparing subject and/or instructor, regardless of format. In an exploratory study of the efficacy of course length and student success in community college developmental education courses, Sheldon and Durdella (2010) discovered that there was a benefit to offering community college developmental education courses in a compressed format, and the benefit extended to all categories of students in terms of both retention of course material and progress through the developmental curriculum. A survey of over 100 faculty members at a large US-based university determined that faculty had different perceptions about teaching a compressed course and made adjustments to the way they taught courses in this format (Eagle, 2012).

\section{Teaching Compressed Courses: Instructor Experiences}

In several articles published in Summer Academe (Arrey, 2009; Crowe, Hyun, \& Kretovics, 2005; Digregorio, 1996-97; Peca, 1996-97), instructors analyzed their own experiences when teaching courses in compressed formats. All concluded that the experiences were positive but that they needed to adjust their teaching approaches and methods.

Peca presented an account of adapting a 16-week, semester-length graduate course to a four-weekend format. She did a number of things to fit the intensive format, including (i) requiring pre-reading of the text, (ii) testing more frequently, (iii) rescheduling tests to better utilize available study time, and (iv) extending the due date of a research paper. Peca concluded that she got to know her students better, and student meetings - normally scheduled in the semester-happened spontaneously in the intensive format.

Digregorio, in an article that discussed the non-classroom interactions between students and faculty, raised an interesting consideration about teaching in summer session. She indicated that in the literature, student development and performance was linked to the quality of student-faculty interaction. She suggested summer session may be the best time to foster this type of interaction in order to benefit students not only in summer session, but throughout the year. Her claim was that summer session, with typically smaller classes, a more relaxed setting, and closer classroom relationships, is an ideal time for faculty to begin to create opportunities for (and reduce the barriers to) interaction with their students.

Crowe, Hyun, and Kretovics discussed their experiences as new faculty members preparing to teach courses in summer session; specifically, they examined teaching methodology, student assignments and assessment, and academic rigour. They determined instructors need to consider changes to teaching methods and student assessment, but elements that define academic rigour (course content, learning goals) should remain unchanged. Further, they suggested that careful consideration be given to the

Canadian Journal of University Continuing Education / Vol. 40, No. 1, spring 2014

Revue canadienne de l'éducation permanente universitaire / vol. 40, no 1 printemps 2014

http://ejournals.library.ualberta.calindex.php/cjuce-rсepu 
time required for students to complete assignments and reading requirements and to assimilate content. In particular, they emphasized the need to modify assignments in compressed courses and to consult with experienced colleagues about teaching in summer sessions. All three faculty members had positive experiences teaching in summer session, noting in particular that it was easier to establish rapport with students and to teach in a more focused way because there was little interference from extracurricular demands, such as committee meetings.

Arrey (2009), in a study based on his own experience teaching a course in an intensive format in summer session versus in a semester-length format, concluded that the intensive format was more beneficial because students focused on a single course in summer session versus multiple courses in the fall or winter semester, and students performed better (i.e., achieved higher grades).

Overall, this literature supports the notion that the quality of the teaching/ learning in compressed-format summer session courses is comparable to when courses are taught in a longer format, and points to a number of advantages of teaching in a compressed format. Further, it identifies how instructors adjust their teaching strategies and approaches in summer session to take advantage of the compressed format.

\section{Best Practices and Benchmarking: Guides to Improved Performance}

Benchmarking is a process designed to improve organizational performance by identifying outstanding (best) practices used by others and adopting them in one's own practice (Mancuso 2001). The benchmarking process begins by identifying critical areas of practice, then determining best practices in each of these areas. In other words, the process involves identifying best practices of individuals or institutions and examining how they do what they do. In the literature, best practices are defined as practices that have been shown to have good results, have been selected using a systematic process, and have been judged as exemplary (Mancuso, 2001). Once identified, best practices can be adopted to improve performance. The intent of this study is to use benchmarking to identify practices of top-rated teachers who teach compressed summer session courses, examine how they do what they do, and outline a set of best practices that others might adopt to improve teaching performance. Specifically, the intent is to develop a set of teacher-based best practices for teaching in compressed summer session courses.

\section{Methodology}

A qualitative methodology was used to gain an understanding of how top-rated instructors teach compressed-format courses. This approach is considered the best way to get close to the phenomena being studied. Among other features, Lincoln and Guba (1985) identified (i) using the researcher as the primary data gathering tool and (ii)

Canadian Journal of University Continuing Education / Vol. 40, No. 1, spring 2014

Revue canadienne de l'éducation permanente universitaire / vol. 40, no 1 printemps 2014

http://ejournals.library.ualberta.calindex.php/cjuce-rcepu 
developing theory inductively from the data as being key to qualitative inquiry; both features are important in this study.

Trustworthiness of the findings was considered by using techniques outlined by Lincoln and Guba (1985), including prolonged engagement, peer debriefing, and member checks. Prolonged engagement means spending sufficient time to get to know the organization. At each university, data were gathered (via interviews) over a two- to three-month period; plus, the researcher had longer contact (greater familiarity) with both universities. Peer debriefing reviewed the process and outcomes of the analysis by having the researcher meet with an informed colleague to help authenticate the interpretation of findings. Finally, informal member checks were used, whereby interpretations gathered in one interview were checked with respondents in subsequent interviews.

\section{Sample}

The study was conducted in two phases. In phase 1, a pool of instructors (in the rank of professor or lecturer) was selected from a large public university in California. In phase 2, a pool of similar instructors was selected from a large public Canadian university. Individuals selected had taught undergraduate courses in two or more summer sessions (within the prior five years), and had taught at least once in a fall, winter, or spring full-length session in the same five-year period. Additionally, instructors were highly rated as summer session teachers, based on university-administered teaching evaluations -i.e., they scored in the top $20 \%$ on teaching evaluations. Finally, the initial sample was reviewed to ensure instructors from a range of departments were included to gain a sense of teaching strategies across a variety of academic disciplines.

Instructors selected were contacted via an email outlining the purpose of the study and inviting them to participate in an interview. Individual consent to participate in the study was based on their agreement to be interviewed. In total, 27 instructors at one university (response rate $30 \%$ ) and 20 instructors at the other (response rate $33 \%$ ) agreed to be interviewed. All interested instructors were contacted by a follow-up e-mail or telephone call to set up an interview.

\section{Data Collection and Analysis}

A semi-structured interview schedule was developed to collect data from instructors about the strategies and approaches they used when teaching compressed summer session courses. This type of interview benefits from a structure that provides consistency of data collection with the spontaneity of a more informal, conversational approach. The preset questions guided the interview within the conversation about teaching. The interview questions were pre-tested with several comparable instructors, and adjustments were made based on the feedback received.

Each instructor was interviewed once, for approximately 60-90 minutes, about teaching in summer session (compressed-format) courses, including course preparation,

Canadian Journal of University Continuing Education / Vol. 40, No. 1, spring 2014

Revue canadienne de l'éducation permanente universitaire / vol. 40, no 1 printemps 2014

http://ejournals.library.ualberta.ca/index.php/cjuce-rcepu 
course delivery, learning environment and students, student assessment (assignments, examinations), and course quality. Instructors were also asked to identify how teaching in summer session differed from teaching in full-length semesters, and to comment on issues and concerns related to teaching in compressed formats. All interviews were recorded and later transcribed. Anonymity and confidentiality were protected, as findings are reported in aggregate form to ensure individuals or their institutions would not be identified. All data were securely stored, then destroyed at the conclusion of the study.

The interview results were analyzed using accepted practices for analyzing qualitative data (Lincoln \& Guba, 1985). The interview data were analyzed on two dimensions: "horizontal" and "vertical." Horizontal analysis viewed the data by question across all respondents, while vertical analysis looked at the data holistically by respondent. Patterns, themes, and categories were developed using the findings displayed in checklist matrices.

\section{FINDINGS}

The findings have been organized into categories that parallel the interview topics: preparing to teach; teaching in the classroom; interaction with students; and classroom environment. Selected examples from instructor interviews are used to illustrate the findings.

\section{Preparing to Teach}

Instructors were asked a series of questions about how they prepare to teach in summer session, specifically related to course design, academic quality, student assessment, and achievement of learning outcomes.

For the most part, instructors indicated they used the same course syllabus in summer session as in the fall, winter, or spring terms but restructured and adjusted the course content to better fit the compressed format. With the intent of making the course fit a compressed time frame, instructors at both universities talked about ensuring they covered the basics while removing superfluous content and trimming the frills-e.g., by offering fewer illustrations/examples or reducing the number of assigned readings. An instructor in education illustrated how she reconsidered the course syllabus when preparing to teach in a compressed format:

I look at the syllabus and determine what can be compressed, what lectures can be merged, what can be dropped. I reformulate my lectures-combine them in new ways - adjust and break lecture topics, which in turn determine where assignments will fall. Overall, I need to play with the pieces a little bit-it's re-chunking. (Instructor 22, Education)

The basis for restructuring depended on a range of factors, including (i) type and mix of students in the course, (ii) the instructor's experience in teaching both

Canadian Journal of University Continuing Education / Vol. 40, No. 1, spring 2014

Revue canadienne de l'éducation permanente universitaire / vol. 40, no 1 printemps 2014

http://ejournals.library.ualberta.calindex.php/cjuce-rсepu 
semester-length and compressed formats, (iii) curricular baselines set by the department (typically for core courses), (iv) requirements for subject majors, (v) outlines available in condensed versions of textbooks, and (vi) requirements set out for professional practice. A chemistry instructor described that he refocused the course content on what nonmajors in biochemistry required:

In summer session, I structure the course around what non-biochemistry majors need to know. I spend more time on introducing and explaining the background-provide foundations and skip some of the advanced topics. I present the big picture versus details on difficult topics. (Instructor 1, Chemistry)

At both universities, instructors indicated using a longer time horizon when preparing to teach compressed courses. Rather than planning a course on a day-today or week-to-week basis, they laid out a detailed plan for the entire term prior to the start of the course. As well, they were quite vocal in stating that they needed to prepare themselves for the intensity of the summer term both mentally and logistically by "clearing the decks" to focus only on teaching. A music instructor succinctly spoke about her planning timeline: "I do a larger overview where I plan what to cover the entire course versus planning for a class or two ahead. I think in terms of larger spans of classes" (Instructor 17, Music). A communications instructor talked about avoiding multitasking in summer session:

[I]n the regular terms I am multitasking like crazy, whereas during the summer I just know it's going to be an intensive time. I don't travel at all. As well, I make my writing commitments separate from the three-week [teaching] period. I'll teach two classes and I'll do nothing but prepare, teach, and grade ... Four to six hours of teaching is a long day. Then I spend the weekend grading. (Instructor 16, Communications)

Instructors were conscious of adjusting assignments and reading requirements to fit the compressed format of summer session. In particular, they expressed concerns about students' ability to complete assignments properly and in a timely fashion and instructors' ability to provide immediate feedback. This was one approach taken by a political studies instructor to compensate for the time pressure: "I set lengthier readings over weekends versus between classes during the week, [and on occasion] substitute reading a book with viewing the DVD (movie) version" (Instructor 4, Political Studies). Some instructors cautioned against setting certain types of assignments in compressed summer session courses, in particular long essays and papers, group assignments, and research papers involving primary research. Others indicated they started assignments earlier in the course, did more quizzing of reading assignments, and defined assignment requirements more carefully. Even though instructors appreciated the summer term contained the same amount of class time, their concern was that the time needed between classes to do these types of assignments was more limited. A communications instructor talked about an approach she used to deal with this challenge:

Canadian Journal of University Continuing Education / Vol. 40, No. 1, spring 2014

Revue canadienne de l'éducation permanente universitaire / vol. 40, no 1 printemps 2014

http://ejournals.library.ualberta.calindex.php/cjuce-rcepu 
The paper assignment is the biggest challenge. There is a question of whether they can do the research for the paper in the compressed time, so I scale back the research paper in summer session, so students do the research but do not fully integrate the information into a research paper. (Instructor 13, Communications)

\section{Teaching in the Classroom}

Instructors were asked about teaching strategies and approaches, variability of instructional methods, use of technology, influence of continuity of class meetings, and the impact of an increased focus on teaching.

Most instructors talked about their teaching in summer session as being basically the same as teaching in other sessions but with some differences. For example, some instructors employed greater interactivity and more in-class group discussion in summer session. Others required students to do more preparatory classwork and preclass reading. A number of instructors were more selective in assigning readings, eliminated role-play activities and/or field trips, relied less on oral reporting in class, and used learning management systems less as a teaching tool.

On the question of depth versus breadth of coverage of content, "the jury is out." Some instructors indicated they did not cover the course in the same breadth in summer session but were able to probe more deeply into select concepts. Others suggested they covered the course in less depth because the intensity and pace required them to spend less time on any one topic in order to cover the breadth of required topics. A law instructor made clear decisions about what to teach:

I need to make choices - to include baseline elements. The decision [is whether] to cut a topic versus providing less depth on some topics. Because of tighter timeframe, there is a need to be more selective-don't cut out topics entirely but rather minimize topics that I don't feel are as essential. (Instructor 6, Law \& Society)

Differences in teaching approaches in the summer term resulted from both compression of the class schedule and continuity of classes. Compression reduces elapsed time of courses, including the available time between classes. At the same time, a compressed schedule increases the length of classes, which allows more time per session. Many instructors felt they were able to get more done in summer term courses because of the intensity and rigour created by the compressed schedule, in which classes meet daily or multiple times per week. This presented an immersion opportunity: students were in daily contact with the course material, with the result that the content was always in mind. As a consequence, there was less need for instructors to spend time reviewing and repeating content, and immediate follow-up could take place on problems and concerns, which allowed students to be more engaged with the material/content of a course. A communications instructor articulated the advantage of teaching in compressed formats:

Canadian Journal of University Continuing Education / Vol. 40, No. 1, spring 2014

Revue canadienne de l'éducation permanente universitaire / vol. 40, no 1 printemps 2014

http://ejournals.library.ualberta.calindex.php/cjuce-rсepu 
[I] spend more time in summer session doing warm up-asking what's going on and getting to know students better. Longer sessions allow me to take more time-more time to clarify things. Students seem more engaged. I use time during breaks to interact with students. (Instructor 16, Communications)

\section{Student Interaction}

Instructors characterized students who attended their courses in summer session as mature (more life and work experience), motivated (to get ahead and finish their degrees), and varied (a greater proportion of visiting and international students). While instructors characterized students as generally motivated, they recognized a clearer distinction in the academic performance of students who attend summer session from those who attend other sessions. The academically strong students were those looking to get ahead (to meet degree requirements early), versus those who were attempting to improve poor performance or repeat failed courses. This reality of summer session teaching was noted by an instructor:

You tend to get students who work harder and you see better performance ... [Y] ou [also] get a crowd of students who tend to be there because they failed the course, but they are not as prevalent as the better students. (Instructor 7, Engineering)

Some instructors at both universities commented on students' ability to handle the compressed schedule in summer session. In their view, students had less time for reflection, for assimilation and absorption of course content, and for incubation of new thoughts and ideas. In addition, some instructors took into consideration students' stamina when deciding on reading requirements, assignments, and pacing of the course, to ensure students were not overwhelmed. This was of particular concern to one of the communication instructors:

[T] here's less incubation time for ideas so that I tend to expect less . . . [T] hey just don't have as much time to assimilate ... I expect them to know a little less detail. I actually ask a little less in summer session, which I don't like to do because I feel if they are getting credit for taking the course, they should take the full course. (Instructor 21)

\section{Classroom Environment}

Instructors were asked to comment on the classroom learning environment in summer session, particularly to comment on their ability to establish rapport with students. Instructors indicated they were able to get to know their students more easily in summer session and develop better relationships; as well, students were able to get to know one another more readily. This was mainly attributed to continuity (meeting

Canadian Journal of University Continuing Education / Vol. 40, No. 1, spring 2014

Revue canadienne de l'éducation permanente universitaire / vol. 40, no 1 printemps 2014

http://ejournals.library.ualberta.calindex.php/cjuce-rcepu 
daily) and the fact that typically, summer classes are smaller. Both these advantages were articulated by an instructor teaching a religion course:

[C]lasses in general are smaller, which means I get to know students better-I know what they can do, I know what they are thinking. I go through an exercise the first week, the first two meetings of the summer session class, which you can't do in a lecture hall of 150 students, but with 25-30 you can learn their names right away ... in the process I learn a lot about them and their interests - and I can't experience that or begin to understand them or know them in the large lecture classes in any significant way. (Instructor 10, Religion)

Instructors also admitted that they were more available to students because of reduced outside commitments, which meant they didn't have to rush away after class. In fact, many instructors indicated that in addition to office hours, they were more available to meet with students before and after classes. The more relaxed and less hectic climate on campus in the summer, which contributed to greater interaction, was captured in the discussion with an accounting instructor:

The university is a huge university and we have large classes, but in summer it switches to this smaller university and there are lots of advantages to that. Obviously, we have smaller class sizes, but it's just not as busy on campus . . . [S]tudents in that environment feel a lot more comfortable developing a one-on-one bond with the instructor ... [A]s the instructor, I feel a lot more comfortable ... In the summer session, I don't feel so resistant to that [being approachable to students]. (Instructor 24, Accounting)

Further, instructors described the classroom environment in summer session as more open, less formal, and more relaxed, which made for more effective teaching (and learning). This was, in part, because they were able to get to know their students better, develop more positive relationships, and gain a fuller sense of their learning experiences. This view was well described by a recreation studies instructor:

I find the summer to be a bit more relaxed and informal ... [T] he summer mindset and summer weather, the students are affected by all that ... [T] hey seem to be more comfortable with sharing and participating. It might also be because they are taking one or two classes so they are able to bring their focus into that [class] to a greater degree. (Instructor 2, Recreation Studies)

Canadian Journal of University Continuing Education / Vol. 40, No. 1, spring 2014 


\section{Best Practices for Teaching in Summer Session}

Examining the practices of instructors who are top-rated for teaching in compressedformat summer session courses provides best-practice ideas that can help instructors and educational administrators to improve the teaching and learning experiences in such courses.

\section{Restructure Courses}

Focus on what needs to be covered. Teaching in compressed format courses requires redesigning the course to fit the compressed schedule. Lee (2002) proposed that faculty teaching in compressed formats focus on what needs to be covered in the course. For example, she suggested that as a planning exercise, instructors consider what they would do if they had to teach a course in three hours (versus several weeks), specifically asking themselves what they would like their students to know and be able to do as a result of the three-hour course.

Determine what students must know. Decisions need to be made on what content is essential versus what can be minimized or left out. Wilson (2007) talked about "prioritized learning," which she broke down into "must know, need to know, and nice to know." "Must knows" are imperative knowledge, prerequisite, and foundational ideas. "Need to knows" are less imperative but likely to be key later. "Nice to knows" add depth or interest to a topic but can be put off without jeopardizing baseline knowledge. The idea is that instructors make decisions on what to include or exclude in a course taught in a compressed format, based on prioritizing learning (i.e., include must knows and need to knows, but not worry if nice to knows are left out). The need-to-know determination may be based on requirements of advanced courses in the discipline, curriculum standards, or requirements of professional practice.

Deal with complex and important topics early. This connects to decisions about what must be included in the course versus what should be included. Given other considerations, like the sequencing of topics, it makes sense to deal with "need to know" topics earlier in the course rather than at the end, when time pressures tend to increase.

Modify processes and structures to fit the faster pace. This could include more breaks within the longer class periods, more shared reading (students assigned different select readings that are reported to the class) and pre-reading assignments, using mixed methods of delivery to vary pace and stimulate interest, including activity-oriented and discussion-focused instruction, and using condensed versions of textbooks to help focus on key components of a course.

Canadian Journal of University Continuing Education / Vol. 40, No. 1, spring 2014

Revue canadienne de l'éducation permanente universitaire / vol. 40, no 1 printemps 2014

http://ejournals.library.ualberta.calindex.php/cjuce-rcepu 


\section{Reconfigure Assignments}

Schedule assignments to fit the "rhythm" of the course. Assignments need to be reconfigured to take into consideration various characteristics of the compressed schedule-frequency of class meeting, limited available time between meetings, and capacity to complete certain tpes of assignments. Lee (2002) suggested instructors develop a general evaluation scheme for the course, based on the expected outcomes, and place assignments and exams appropriately in the course timeline. For example, longer assignments and more complex readings could be scheduled over longer breaks in the week or over weekends.

Deconstruct single longer assignments. Instructors should create more frequent shorter assignments, schedule the first assignment early in the course to have students start immediately, and provide early feedback to enhance motivation and performance. For larger assignments due later in the course, require preliminary assignment outlines that count towards the grade.

Relocate activities/assignments. This could include moving assignments/activities from in-class (typical in full-length terms) to outside of class time. For example, require students to view materials online outside of class versus as part of an in-class presentation, to maximize class time for other activities. Also, use pre- and post-course assignments to spread the workload beyond the compressed class schedule.

Choose assignments that fit schedule. Instructors should avoid long essays and papers, group assignments, and research papers involving primary research. In addition to the time required to do these types of assignments, they increase the challenge for instructors to provide timely feedback to students within the compressed summer term.

\section{Organize and Plan for the Term}

Plan over a longer time horizon. Planning should be done for the entire course/ term, including scheduling opportunities for instructor-student interaction. Planning needs to take into consideration the requirements, contingencies, and differences in the compressed schedule. As with all teaching, good organization is critical to any successful teaching experience, but it is particularly important when teaching faster paced, compressed courses.

Check the pace regularly. This is one of the advantages of planning the entire course. Most importantly, check with students about the pace of the course. One instructor used a simple "Goldie Locks and the Three Bears" type scale to regularly measure whether students were managing the pace, by asking whether the pace was too slow, too fast, or just right.

Canadian Journal of University Continuing Education / Vol. 40, No. 1, spring 2014

Revue canadienne de l'éducation permanente universitaire / vol. 40, no 1 printemps 2014

http://ejournals.library.ualberta.calindex.php/cjuce-rcepu 
Coach students on time management. Time management skills help students keep up with the faster pace of compressed courses. Instructors need to remind students about the importance of beginning course work early and warn against overextending with too many outside activities.

"Clear the decks" logistically and mentally. Instructors need to give their full attention to teaching during the compressed term. Top-rated instructors advised against teaching more than one compressed course at a time and suggested avoiding teaching a course for the first time in summer session. The significance of this caution will depend on teaching experience, because many experienced instructors use the summer session to experiment with new courses and course delivery.

\section{Capitalize on Continuity and Smaller Classes}

Take advantage of continuity of class meetings. Instructors are not required to frequently review and re-set class agendas; instead the continuity of class meetings allows for a more seamless teaching/learning experience and increased time on task, which has students more engaged in the course.

Take time to get to know students. Instructors need to take advantage of smaller, more relaxed classes in summer session to recognize and respond to students more personally. According to Lee (2002), the notion of engagement includes setting a relaxed classroom environment and creating a sense of community through discussion, group work, guided reflection, and other activities that promote student interaction. This, in turn, helps learners to connect with course material, the instructor, and fellow students.

\section{Maximize Supports to Students}

Be more available to students. Instructors should schedule longer and more frequent office hours and arrive early and stay after class. Even though the class time is equivalent, students do not have as much opportunity to connect with instructors over the compressed term. Creating opportunities to meet provides students with a chance to deal not only with academic issues but also with other related issues that can affect student retention and performance.

Provide supports, organizers, and guides. These supports potentially increase student success and could include advanced organizers that set out workload and expectations, guides to textbooks and assigned readings that outline must-reads (i.e., those of primary importance), plus a list of discussion/reflection questions to help students focus on key issues.

Canadian Journal of University Continuing Education / Vol. 40, No. 1, spring 2014

Revue canadienne de l'éducation permanente universitaire / vol. 40, no 1 printemps 2014

http://ejournals.library.ualberta.calindex.php/cjuce-rcepu 
Supply prepared lecture notes. While note taking may be considered work that students should be doing, handouts or online notes ensure students have the basic information contained in lectures and presentations. This is especially important in faster-paced, compressed-format courses. The approach gives instructors the opportunity to shift class time from information giving to interaction and discussion.

Overall, top-rated instructors emphasized that expectations and standards should not be lowered in courses taught in compressed formats. In their view, redesigning a course, selectively determining reading requirements, and adjusting assignments and tests did not result in lowering standards and expectations. On the contrary, many felt these changes for teaching in a compressed format created a better learning experience for students. While top-rated instructors kept to the same basic teaching approaches, they recognized the importance of making adjustments to meet the requirements of a compressed schedule, and to take advantage of smaller classes, continuity of class meetings, and the more relaxed and informal campus in summer. It is important to capitalize upon the differences of teaching in a compressed format.

\section{CONCLUSION}

Instructors were asked to construct a metaphor that was illustrative of their summer session teaching experience. One instructor used a coffee metaphor: "Teaching in summer session is like drinking a cup of espresso versus drinking a cup of American coffee." Another talked in terms of acting in a play: "Teaching is like being in a play; you are interacting with the audience [students], but it's a different type of play in summer session - it's more intense, and I am on the stage for longer." A third offered an image of containers of soup: "The content of the course is like a quart jar of soup: summer session requires that you fit the soup into a smaller jar, but as you attempt to get the soup into the smaller jar, some spills over. You have to be okay with some broth spilling, letting some broth go, but you need to be skilled to ensure that the hearty components of soup get into the smaller jar."

These metaphors represent different perspectives on teaching in a compressed format-it is more concentrated, more intense, and requires more attention to course redesign. The best practices outlined in this paper focus on these features and provide guidance on how to maximize the quality of instruction. As indicated in the literature, the quality of the learning experience in courses taught in compressed formats is comparable to courses taught during the full-length term, when instructional quality is high. Adopting best practices, those used by top-rated instructors, can help to improve teaching performance and, in turn, the quality of the learning experience in compressed-format courses.

As with any qualitative study that examines a limited sample (in this study, two large, public universities with long-established summer sessions), there is the issue of

Canadian Journal of University Continuing Education / Vol. 40, No. 1, spring 2014

Revue canadienne de l'éducation permanente universitaire / vol. 40, no 1 printemps 2014

http://ejournals.library.ualberta.calindex.php/cjuce-rсepu 
transferability of findings. As noted by Lincoln and Guba (1985), it is the responsibility of the qualitative researcher to provide information that allows others to judge the applicability to their setting. The description of both the instructor sample and the institutions should allow others to determine whether there is a fit with these best practice recommendations.

There is reason to believe that the use of technology would be a best practice when developing and teaching courses in compressed formats, specifically when the pace of teaching/learning is increased. In particular, the use of blended learning approaches (i.e., the integration of face-to-face and online instruction) promises to enhance learning both in and outside the classroom (Collis, 2002). Interestingly, the instructors in this study gave little attention to the use of technology other than basic classroom teaching aids.

Continued research on top-rated instructors is important, particularly at universities with differing characteristics (i.e., type and size) from the institutions studied. By examining practices at other universities and colleges, the identified best practices may be both refined and expanded. As well, the perspectives of learners could be studied to determine what teaching/learning practices contribute to the quality of their learning experiences in compressed-format courses.

Implementing best practices requires taking into account potential resistance to change, identifying performance gaps, and developing a process to integrate new practices into teaching approaches. Commonly at universities and colleges, such new practices are part of faculty development programs. Those responsible for developing and managing courses taught in summer session are encouraged to work with instructional development units on their campuses to offer programs specific to teaching in compressed-format courses.

Overall, the findings of the study compare to what other researchers identified as important to achieving quality teaching in compressed formats. Top-rated instructors indicated they approached teaching compressed-format courses in summer session differently from teaching courses in full-length terms with respect to course planning, classroom instruction, student assessment, and interaction with students. These practices are important to quality teaching regardless of the format, but appear to be more critical when courses are delivered in a compressed format.

Canadian Journal of University Continuing Education / Vol. 40, No. 1, spring 2014

Revue canadienne de l'éducation permanente universitaire / vol. 40, n 1 printemps 2014

http://ejournals.library.ualberta.calindex.php/cjuce-rcepu 


\section{REFERENCES}

Anastasi, J. S. (2007). Methods and techniques: Full-semester and abbreviated summer courses. Teaching Psychology, 34(1), 19-22.

Arrey, L. N. (2009). Organic chemistry: Intensive format or traditional format. Summer Academe, 6, 37-45.

Collis, B. (2002, November 25). The net as a tool for blended learning. What are the ingredients for success? Paper presented at Netlearning, Ronneby, Sweden.

Crowe, A., Hyun, E., \& Kretovics, M. (2005). Reflections on summer teaching: Academic rigor or curriculum light? Summer Academe, 5, 7-20.

Daniel, E. L. (2000). A review of time-shortened courses across disciplines. College Student Journal, 34(2), 298-308.

Digregorio, K. (1996-97). Essential encounters: Non-classroom interactions between students and faculty. Summer Academe, 1, 13-26.

Eagle, T. (2012). A survey of university teaching practices and perceptions of compressed courses. M.S. Thesis, University of Illinois at Urbana-Champaign. Retrieved from https://www.ideals.illinois.edu/handle/2142/42141

Gaubatz, N. (2003). Course scheduling formats and their impact on student learning. The National Teaching and Learning Forum. Retrieved from http://206.62.142.44/html/ lib/suppmat/1201course.htm

Lee, S. L., \& Mroczka, M. (2002). Teaching in intensive course formats: Towards principles of effective practice. Paper presented to North American Association of Summer Sessions Annual Conference, Baltimore, Maryland.

Lee, V. (2002). Teaching summer session courses. Professional Development Seminar, The Faculty Center for Teaching and Learning. Raleigh, NC: North Carolina State University.

Lincoln, Y. S., \& Guba, E. G. (1985). Naturalistic inquiry. London, UK: Sage.

Lutes, L., \& Davies, R. (2013). Comparing the rigor of compressed format courses to their regular semester counterparts. Innovative Higher Education, 38(1), 19-29.

Mancuso, S. (2001). Adult-centered practices: Benchmarking study in higher education. Innovative Higher Education, 25(3), 165-181.

Martin, H., \& Culver, K. (2007). Concentrate, intensify, or shorten: Short intensive courses in summer session. Continuing Higher Education Review, 71, 90-100.

Peca, K. (1996-97). Intensive instruction: Lessons from the field. Summer Academe, 1, 57-62.

Scott, P. A. (2003). Attributes of high-quality intensive courses. New Directions for Adult and Continuing Education, 97, 29-38.

Canadian Journal of University Continuing Education / Vol. 40, No. 1, spring 2014

Revue canadienne de l'éducation permanente universitaire / vol. 40, n 1 printemps 2014

http://ejournals.library.ualberta.calindex.php/cjuce-rсepu 
Sheldon, C. Q., \& Durdella, N. R. (2010). Success rates for students taking compressed and regular length developmental courses in community college. Community College Journal of Research and Practice, 34, 39-54.

Shoemaker, J. (2009). Instructional quality of summer courses at UCI. A report for the Council on Educational Policy. Division of Undergraduate Education, University of California Irvine. Retrieved from http://www.assessment.uci.edu/documents/final_ report_summer_instructional_quality.pdf

Swenson, C. (2003). Accelerated and traditional formats: Using learning as a criterion for quality. New Directions for Adult and Continuing Education, 97, 83-92.

Wilson, L. O. (2007). When backward is forward thinking: Radical changes in instructional designs for summer school. Presentation at the North Central Conference of Summer Sessions Annual Conference, Chicago, IL.

\section{BIOGRAPHY}

William J. Kops is a professor and the Director of Summer Session and General Studies at the University of Manitoba. He teaches courses in adult and continuing education. His research interests are on issues related to summer session administration, continuing learning of older adults, and self-directed learning.

William J. Kops est professeur et directeur de la session d'été et des études générales de l'Université du Manitoba. Il enseigne aussi aux adultes dans des programmes d'éducation permanente. Ses recherches portent sur les enjeux liés à l'administration des sessions d'été, à l'apprentissage continu des aînés et à l'apprentissage autodirigé.

Canadian Journal of University Continuing Education / Vol. 40, No. 1, spring 2014

Revue canadienne de l'éducation permanente universitaire / vol. 40, no 1 printemps 2014

http://ejournals.library.ualberta.calindex.php/cjuce-rcepu 